\title{
MI PERSPECTIVA VIQUIANA
}

\section{Francesco Botturi \\ (Universidad Sacro Cuore de Milán)}

RESUMEN: Las doctrinas del verum ipsum factum y del universal fantástico sitúan de modo peculiar la obra viquiana en el contexto de la filosofía moderna y se abren hacia una original epistemología hermenéutica y a un diagnóstico de la civilización todavía actual.

PALABRAs ClaVE: Vico, $350^{\circ}$ Aniversario, modernidad (viquiana), universal fantástico, hermenéutica, humanismo y barbarie, F. Botturi.

\section{My Vichian perspective}

ABSTRACT: The doctrines of the verum ipsum factum and the fantastic universal situate the work of Vico in a peculiar place in the context of modern philosophy and opening themselves towards an original hermeneutical epistemology and towards a diagnosis of civilization that is still in force.

KEYWORDS: G. Vico, 350 th Anniversary, modernity (vichian), fantastic universal, hermeneutics, humanism and barbarism, F. Botturi.

\section{La mia prospettiva vichiana}

RIASSUNTO: Le dottrine del verum ipsum factum e dell' universale fantastico fanno sì che l'opera vichiana occupi uno spazio peculiare nel contesto della filosofia moderna e aprono a un'epistemologia ermeneutica originale e a una diagnosi della civiltà ancora attuale.

PAROLE CHIAVE: Vico, $350^{\circ}$ Anniversario, modernità (vichiana), universale fantastico, ermeneutica, umanesimo e barbarie, F. Botturi.

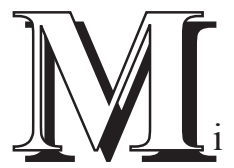

i interés por G.B. Vico proviene de un estudio sobre el tema de modernidad y ateísmo en el que tuvo un significado particular la obra de Augusto Del Noce Il problema dell'ateismo, ${ }^{1}$ que proporciona a la investigación sobre las raíces del ateísmo moderno una idea plural de la modernidad filosófica. A partir de Descartes se originaron dos "modernidades" distintas, dos genealogías especulati-

Este artículo responde a una invitación expresa por parte de la Dirección de la Revista para este volumen especial por el $350^{\circ}$ Aniversario del nacimiento de G. Vico, habiendo superado los criterios de valoración y del proceso de aceptación. 
vas opuestas e irreductibles; una racionalidad que conduce a Hegel y a su contestación de Izquierda, la otra "agustiniana", que conduce a Rosmini. En esta segunda línea tienen una función sobresaliente Pascal, Malebranche y Vico. Me resultó sugerente la tesis de que la modernidad hiciera posible, incluso correcto, llevar a cabo una lectura múltiple, transgresora de la escolástica racionalista, según la cual existe la modernidad como parábola única desde Descartes a Hegel, eventualmente a Nietzsche (cfr. K. Löwith); con los corolarios de la subordinación del pensamiento religioso al paradigma racionalista y de la legitimación del éxito ateo de la modernidad misma. Eso era en suma motivo más que suficiente para intentar verificar dichas tesis comprometedoras respecto a un Vico entendido no como autor quizá original, pero no obstante marginal en la historia de la filosofía, sino como protagonista del curso de la gran filosofía moderna y de sus problemáticas fundamentales.

A finales de los años Setenta la literatura viquiana internacional presentaba un panorama desigual, pero también fuertemente innovador, derivado del hito producido por la avalancha de estudios viquianos con ocasión del tricentenario (1968) del nacimiento del Autor, ${ }^{2}$ que ya prescindía de la clásica monografía de Croce como paradigma no superado de una interpretación, que consistía justamente en la magistral operación de inserción de la obra viquiana en la línea de la filosofía moderna que conducía a Hegel (en un sentido exactamente contrario a la dirección de Del Noce). Mi elección de trabajo sobre Vico fue entonces el buscar un hilo conductor con el que encontrar una trayectoria reconstructiva -fundamentada lo más posible en los textos- de la arquitectura de la obra viquiana. Un trabajo, pues, no limitado a un tema particular, pero tampoco una pretenciosa reconstrucción total de todas las partes, sino más bien una obra que restituyera -si era posible- justamente la arquitectura del pensamiento viquiano, es decir, su planta, sus materiales de construcción, la proporción entre sus partes; premisa de ulteriores investigaciones sobre un Vico iuxta propria principia, que se sustrajese a la tendencia -presente de distinta manera también en la nueva literatura internacional- de casar a Vico con cualquier otro gran autor (Locke, Kant, Nietzsche...) tras su residencia forzada junto a Hegel.

\section{LA MODERNIDAD VIQUIANA}

Después de una década de estudio se publicó mi mayor obra viquiana $L a$ sapienza della storia. G.B. Vico e la filosofia pratica, ${ }^{3}$ cuyo título pretendía señalar el resultado global de la investigación, o sea, que el régimen especulativo pre-

1. A. Del Noce, Il problema dell'ateismo. Il concetto di ateismo e la storia della filosofia come problema, il Mulino, Bolonia 1964. Siguiendo mis estudios viquianos se profundizó también mi conocimiento de Del Noce y a la vez una cierta revisión crítica de su interpretación de Vico (cfr. F. BotTURI, «Vico nel pensiero di A. Del Noce», en AA.VV., Augusto Del Noce: Il problema della modernità, Studium, Roma, 1995, pp. 95-106).

2. Hito del cual el volumen AA.VV., Omaggio a Vico (Morano, Nápoles, 1968) constituyó un síntoma importante y un episodio sobresaliente.

3. F. BotTuri, La sapienza della storia. G.B. Vico e la filosofia pratica, Vita e Pensiero, Milán, 1991. 
valente en Vico es de orden antropológico, en sentido tanto epistemológico como práctico. El debate viquiano inicial con el cartesianismo está bajo el signo del problema de la verdad accesible al hombre y de sus formas («crítica» y «tópica»), en el que Vico reivindica en cierto sentido la primacía de la experiencia y en esta del saber práctico operativo. Considerado de modo más amplio, podría decirse que, a los ojos de Vico, la unilateralidad de tipo cartesiano sería un factor y un síntoma de una cierta descomposición de la experiencia, en el que con lo práctico están todos los órdenes del hacer, del actuar, del pertenecer (a una tradición), del relacionarse y del comunicar que están marginados y privados de dignidad teórica. En este sentido, la experiencia sufre una serie de sustracciones, del cuerpo, de la sensibilidad, de la imaginación, de la operatividad, de la sociabilidad, de la historicidad, que no responden a los parámetros de verdad crítico-científica. La recuperación de la verdad práctica permite repensar el universo de la acción y las condiciones de la constitución del mundo humano, que el cartesianismo ignoraba metodológicamente y que las formas modernas de razón práctica (de Maquiavelo a Montaigne y Charron, a Hobbes) interpretaban en sentido pragmático, escéptico, materialista.

La doctrina del verum ipsum factum es fundadora y sintetizadora del empeño especulativo viquiano. Por mi parte, propuse una hermenéutica que me parece que tiene en cuenta el propósito declarado por Vico de conectar la dimensión inmanente y la transcendente de su antropología, el carácter contemplativo y el productivo del saber, la unidad y la pluralidad de la verdad. Sin ocuparme aquí de ello, recuerdo solo que para Vico el conocimiento humano es una participación, necesariamente limitada, del conocimiento divino, que lo verdadero está presente en idea en la mente del hombre, pero se expresa necesariamente en las formas producidas por él (copresencia de intuicionismo y constructivismo), que, por tanto, la verdad se da según el doble régimen de su unidad fundamental y de su pluralidad histórica. No estamos lejos del "frontispicio" que se colocará al inicio de la segunda edición de la Scienza nuova: el único rayo de la luz divina se refracta sobre el pecho de la metafísica (de la mente) humana y se despliega en las muchas formas del actuar humano histórico, que ya no son, pues, meros hechos, sino que portan en sí una luz de verdad. Inmanente a la mente humana y a sus productos existe por eso siempre una dimensión transcendente, es decir, una transcendencia que se abre desde el interior de la inmanencia. La metafísica de Vico está contenida así en el genitivo subjetivo de la «metafísica de la mente», premisa de su concepción de la «Providencia».

\section{EL ALCANCE ESPECULATIVO DEL UNIVERSAL FANTÁSTICO}

Es a este nivel donde se coloca la mayor novedad especulativa de la filosofía viquiana; la más subversiva del racionalismo moderno, la más rica en con- 
secuencias antropológicas y, a la vez, la menos comprendida y la más abandonada ya por los primeros discípulos: ${ }^{4}$ la doctrina del género poético o universal fantástico. El presupuesto gnoseológico está incluido en la facultad del ingenio, que Vico -retomando la Denkform barroca- identifica con el centro de la capacidad cognoscitiva humana, a medio camino entre sensibilidad e intelectualidad, justamente como capacidad de unificación creativa de los datos sensibles (y en este sentido metasensibles) y como capacidad de formular un casi universal en forma de una imagen paradigmática y matriz de muchas otras imágenes. Además, la idea de ingenio que Vico revitaliza está estrechamente unida a la dimensión lingüísti$c a$ (no solo verbal) de la experiencia; el ingenio no trabaja con significados alálicos, sino también con los significantes, como es bien evidente en la cultura barroca de la época, con sus exuberantes y extraordinariamente creativos lenguajes metafóricos. El ingenio es, así, también sustancialmente ingenio lingüístico, y como tal generador de mundos. Aquí se encuentra la distancia máxima frente al cartesianismo, caracterizado más bien por una idea del saber independiente de su cuerpo lingüístico; mientras que en Vico, anticipando mucho el giro lingüístico en filosofía, el lenguaje es mediación insuperable entre cuerpo y mente y, por consiguiente, también entre mente y acción; la concepción lingüística viquiana no es, pues, solamente semántica, sino también pragmática; es a la vez -podríamos decir-escénica y "teatral”, como lo será en su conjunto la propia escritura viquiana de madurez.

De este modo, Vico afronta un problema central de la filosofía moderna, el de la bifurcación entre sensibilidad y racionalidad, de la que se veían señales en el racionalismo cartesiano, pero también en el intelectualismo de la filología erudita y en el del nuevo iusnaturalismo, en la fantasmagoría hedonista del imaginario manierista y conceptista y en las distintas formas del epicureísmo y del materialismo del tiempo. Más en general, Vico afronta, a su original modo, la cuestión de la relación entre universal y particular, tomando el nivel en el cual se da su originaria atadura, que impide su bifurcación en dirección racionalista o empirista con todas las consecuencias epocales de orden teórico y cultural. Así, en Vico es posible recuperar el fondo simbólico del conocimiento, la capacidad mitológica de la mente, la verdad narrativa del lenguaje, con los cuales el hombre construye su mundo mediante una espontaneidad radicada en la sensibilidad pero ya "racional", culturalmente ya rico de sentido aunque intelectualmente aún primitivo, aún poco reflexivo pero ya capaz de producir formas sabias de convivencia, rudas y conflictivas, pero ya orientado hacia una progresiva universalidad.

4. Cfr. F. BotTuRI, «Umanesimo linguistico e filosofia civile in G.B. Vico. Sentiero interrotto della cultura italiana», en A. BIANCHI (ED.), Storia, civiltà e religione in Italia, Studi in occasione del $150^{\circ}$ anniversario dell'unità d'Italia, Vita e Pensiero, Milán, 2014, pp. 213-224. 


\section{LA FILOSOFÍA HERMENÉUTICA de ViCo}

Prosiguiendo en el estudio del texto viquiano, me di cuenta de que en su novedad especulativa está implícita una metodología hermenéutica. La filosofía de la «ciencia nueva» debería hacer merecedor también a Vico del título de fundador de la hermenéutica filosófica moderna (como había sostenido, sin ser escuchado, E. Betti ${ }^{5}$ ). Como he podido reflejar en algunos escritos subsiguientes a mi volumen de 1991, ${ }^{6}$ la epistemología hermenéutica de Vico se documenta de forma sistemática en su reunificación de «filosofía» y «filología», de razón y lenguaje, como vía metodológica para llegar a la realidad histórica, en su dúplice valencia de realidad cultural refleja y de espontaneidad mitopoiética religiosa, jurídica y política. La «ciencia nueva» viquiana, integrando la metodología filológica humanista con un cierto platonismo de la «mente», se realiza como hermenéutica del evento: los acontecimientos lingüísticos, testimoniados por la tradición erudita de la «filología», se convierten en eventos en cuanto son interpretados según el criterio del sentido suministrado por la «mente» y por sus «modificaciones».

Pero basta poca atención para darse cuenta de que la estructura bipolar y su movimiento circular no son propias solo de la unión de filosofía y filología, sino de toda la obra viquiana. «Tópica» y «crítica» en el De ratione y en el De antiquissima; auctoritas y ratio, certum y verum en el Diritto universale; «ingenio» y «razón», «sentido» e «intelecto», «sabiduría vulgar» y «sabiduría culta», «poesía» y «filosofía» en la Scienza nuova son hendíadis que rigen toda la arquitectura del pensamiento viquiano. La "ciencia", donde cooperan "filología" y "filosofía", no es entonces más que el nivel temático en el que se reflejan la estructura y el movimiento del espontáneo acontecer humano, que es ya en sí mismo evento hermenéutico.

Por ello, resulta fundamental el ritmo de espontaneidad y de reflexión que señala una recíproca superioridad del momento creativo y del crítico, que es densa de significado. La primacía cronológica de la espontaneidad, en efecto, es indicio de lo indeducible del sentido y de lo inasible de su origen: el origen del acontecer es ejercitado y transmitido antes de todo su ordenamiento lógico reflejo; el origen del sentido solo puede pensarse siempre como ya dado y precedente siempre a su comprensión. A su vez, la superioridad explicativa de la reflexión está en su ser manifestación de la verdad del sentido, es decir, comprensión del "orden" del sentido en su génesis

5. Cfr. E. BetTI, Diritto Metodo Ermeneutica, edit. por G. CRIFò, Giuffrè, Milán, 1991, p. 485.

6. F. BotTURI, «Ermeneutica dell'evento. La filosofia dell'interpretazione di G.B. Vico»,* en AA.VV., La filosofia pratica tra metafisica ed antropologia nell'età di Wolff e Vico, a cargo de G. CACCIATORE-V. GESSA-KuROTSCHKAH. Poser-M. Sanna, Guida, Nápoles, 1999, pp. 447-470; ID., «L'etica ermeneutica di Giambattista Vico», en AA.VV., Etica individuale e giustizia, editado por A. Ferrara, V. Gessa KurotschKa, S. Maffettone, Liguori, Nápoles, 2000, pp. 213-239; ID., «Ermeneutica del mito ed esperienza etica in Giambattista Vico», en AA.VV., Pensar para el nuevo siglo. G.B. Vico y la cultura europea, E. Hidalgo-Serna, M. Marassi, J.M Sevilla, J. Villalobos (editores), La Città del Sole, Nápoles, 2001, vol. I, pp. 275-293. [*En español en Cuadernos sobre Vico, n. 9-10, 1998, pp. 43-56. N.E.] 
y de su estructura, en su acontecer espontáneo y en su transcurrir necesario. La circularidad entre espontaneidad y reflexión se configura, por ello, como círculo de precomprensión y comprensión, porque no solo la «sabiduría vulgar» constituye la precomprensión necesaria para entender correctamente la «sabiduría culta», sino también porque esta es auténtica si se comprende como originada por la «sabiduría vulgar».

\section{HUMANISMO Y BARBARIE}

Finalmente, me parece que la filosofía viquiana debe ser hoy más valorada por su importancia diagnóstica de civilización. ${ }^{7}$ El de Vico acerca de la historia es un pensamiento genealógico, que se concreta en un pensamiento sobre el origen de la humanitas, de sus condiciones de existencia, de su relación permanente con la barbarie. Es este un punto capital de la construcción viquiana, que se refiere a la naturaleza de lo social y al fundamento de lo político en vista de la crisis moderna de la relación entre lógos y pólis. Ya el Diritto universale pone en la base de la sociedad humana la obra de los patres (los primeros hombres escapados de la feritas postlapsaria, convertidos en fundadores de grupos sociales a partir de la comunidad de familias) en cuanto poetas, teólogos, políticos, en la que se evidencia la posición intermedia y mediadora del ser poetas (creadores de formas) respecto al ser teólogos (abiertos a lo divino) y políticos (fundadores y regidores de «naciones»); la sabiduría de los patres, fundadora de la realidad como mundo en oposición al caos post-paradisíaco, compone el sentido con la invención de los mitos primordiales, que estructuran el horizonte de la experiencia en términos de relación religiosa vertical y de relación jurídico-política horizontal.

La conjunción de lo poético, lo religioso y lo jurídico constituye así la estructura basilar de lo social y de lo político y, a la vez, el criterio de refutación de las visiones utilitarias de derivación materialista (de Epicuro hasta Maquiavelo, Hobbes, Spinoza, Bayle) o racionalista (Grocio y Pufendorf, por último, asimilados a los precedentes). La utilidad, efectivamente, no puede ser «causa» de socialización, sino solo «ocasión», a fin de que un ulterior y más inclusivo factor pueda comunicar y asociar a los individuos como miembros de un todo superior. Sin esta llamada a un vínculo ulterior meta-utilitario los hombres no tienen motivo de relación que no sea utilitaria, lo que no puede concluir más que en una «sociedad que fuese de mercaderes», ${ }^{8}$ sustanciada por intereses divergentes y confluyentes.

Esta capacidad típicamente humana de tomar distancia desde la inmediatez sensible pulsional tiene que ver con el sentido común viquiano, que concentra en sí

7. Cfr. F. BotTurI, «Giambattista Vico: la storia come umanesimo diacronico», Studium, 108, 2, 2012, pp. 167-178; «Humanism and Barbarism. The Crisis of European Consciousness», en E. BAlboni y A.M. CASCETTA (EDS.), European Cultural Identity. Law, History, Theater, Art, Ets, Pisa, 2018, pp. 139-154.

8. Principi di scienza d'intorno alla comune natura delle nazioni, 1744. En Opere filosofiche, edición a cargo de P. Cristofolini, Sansoni, Florencia, 1971, p. 462. 
mismo el contenido esencial y universal de la sabiduría vulgar, atestiguada por los tres «principios del universo civil». Tres grupos de creencias normativas que se refieren a las «costumbres» esenciales de la humanitas constitutiva de las naciones: los matrimonios, como estabilidad de la dimensión temporal genealógica entre géneros y generaciones; las sepulturas, como estabilidad de la dimensión espacial en la relación con el territorio convertido en sagrado; la confianza en la Providencia, como estabilidad de relaciones con lo divino eterno que opera dentro del acontecer espaciotemporal en sinergia con la iniciativa humana.

Es el sentido común lo que fundamenta y permite el desarrollo del humanismo social originario, en cuanto elemental, espontánea e insuperable apertura del hombre más allá de sí mismo, su clausura pulsional, su soledad, su misma mortalidad. La «ciencia nueva», en efecto, es saber de la «común naturaleza de las naciones», es decir, del lugar de nacimiento de lo humano e históricamente lugar de renacimiento tras la caída hacia el origen y la ventaja de la barbarie primitiva. ${ }^{9}$ El humanismo de la relación y de la comunicación asoma, pues, sobre el fondo oscuro de la barbarie de la soledad y del conflicto, que no obstante es generadora porque está dotada de una apertura progresiva a la transcendencia horizontal y vertical a través de las formas mito-poéticas del sentido común y acomunante.

Otro es, por el contrario, el significado de la barbarie que al final de la Scienza nuova de 1744 Vico propone con clara referencia a su época: la barbarie que acecha desde el interior a una civilización como la moderna, llegada a una nueva fase de desarrollo técnico y de organización política; segunda barbarie «maliciosa», según el término viquiano, porque realiza el tránsito exactamente contrario al primitivo, que reconduce a las formas sociales existentes hacia el individualismo separador y hostil, hasta volverlas bárbaras y corromperlas del todo con «desenfrenada libertad», «total desorden», «anarquía» y «guerra civil», como explica Vico.

A la luz del pensamiento viquiano la "crisis de la conciencia europea" (1680-1715, según la periodización propuesta por P. Hazard) representó una crisis del conocimiento de los fundamentos comunes de las naciones y de sus grandes tradiciones culturales. A la Europa de la nueva ciencia galileana, de la nueva "crítica" cartesiana, de la nueva política hobbesiana, de la nueva burguesía mercantil, del nuevo iusnaturalismo post-clásico, le falta un pensamiento adecuado, una ciencia nueva acerca de la génesis de la civilización proporcionada al cambio de época. Lo impensado o lo malpensado de la segunda modernidad versa sobre las razones de comunidad no confesional y de convivencia que surgen de las condiciones genéticas y estructurales de la civilización humana.

En la crisis contemporánea de los "grandes relatos" el problema vuelve a plantearse. Tampoco la democracia, gran beneficio político metodológico, incluye

9. Cfr. F. Botturi, «Caduta e storia. Note sul "peccato originale" in G.B. Vico», Rivista di Filosofia neo-scolastica, 1 enero-marzo 2005, pp. 29-54. 
en sí misma como tal una razón fundacional suficiente de la convivencia, porque de suyo la idea democrática remite a un fundamento de valor que la precede y la transciende (según la paradoja de Böckenförde); por lo que, por ejemplo, puede desleírse en un régimen de derechos subjetivos según necesidades y deseos que desencadena un proceso de divergencia ilimitada entre los intereses; mientras, en condiciones de progresiva globalización, la fuerza agregante real parece convertirse cada vez más en algo similar a una tecnocracia meta-política y meta-democrática. Un mundo globalizado por la tecno-estructura no garantiza en absoluto la capacidad de convivencia plural y política, porque pretende unificarse prescindiendo, cuando no yendo en contra, de las «naciones» y su historia, sus modos de vida, sus creencias.

La regresión bárbara es medida por Vico en proporción al eclipse cultural del "sentido común". El paso a la edad de los hombres y la prevalencia en ella de la razón desplegada y reflexiva puede realizarse oscureciendo la importancia fundadora de los orígenes, como si no fuese un precedente indispensable y no identificase un perfil antropológico permanente. Se pierde de ese modo la memoria activa de la unidad mito-poiética de las dimensiones de la experiencia (cognitiva, estética, religiosa, moral, social), más importante que toda su articulación especializada, porque mantiene vivo el ejercicio de la apertura radical de la mente y de sus símbolos narrativos, en la cual está la fuente de esa «naturaleza» que acomuna a las naciones. Se revierte así el basilar sentido de pertenencia a favor de la soledad individualista y con ello viene a menos el respeto privilegiado por los lugares generadores por excelencia (matrimonio y familia) y por el evento genealógico esencial que es la muerte (privatización de la muerte). La civilización, pues, desde el punto de vista viquiano da pasos decisivos hacia la barbarie retornada. La irreligiosidad, la precarización de la institución familiar y la manipulación de la reproducción, la desacralización de la muerte y su gestión artificial -formas plenamente actuales disolutorias del «sentido común»- no pueden sustraerse a un cuestionamiento de sentido acerca de los fundamentos de la convivencia y a una duda sobre la frontera entre humanismo y barbarie.

[Traducido del italiano por María José Rebollo Espinosa] 